\title{
Coccygeal Morphology on Multislice Computed Tomography in a Tertiary Hospital in India
}

\author{
Venkatraman Indiran ${ }^{1}$, Vadivalagianambi Sivakumar ${ }^{2}$, Prabakaran Maduraimuthu ${ }^{1}$ \\ ${ }^{1}$ Department of Radiodiagnosis, Sree Balaji Medical College and Hospital, Chennai, India \\ ${ }^{2}$ Department of Radiodiagnosis, Meenakshi Medical College Hospital \& Research Institute, Kanchipuram, India
}

Study Design: A retrospective, cross-sectional study of 213 patients who presented for abdominal computed tomography (CT) scans to assess coccygeal morphology in the Indian population.

Purpose: There have been relatively few studies of coccygeal morphology in the normal population and none in the Indian population. We aimed to estimate coccygeal morphometric parameters in the Indian population.

Overview of Literature: Coccygeal morphology has been studied in European, American, Korean, and Egyptian populations, with few differences in morphology among populations.

Methods: A retrospective analysis of 213 abdominal CT scans (114 males and 99 females; age, 7-88 years; mean age, 47.3 years) was performed to evaluate the number of coccygeal segments, coccyx type, sacrococcygeal and intercoccygeal fusion and subluxation, coccygeal spicules, sacrococcygeal straight length, and sacrococcygeal and intercoccygeal curvature angles. Results were analyzed for differences in morphology with respect to sex and coccyx type.

Results: Types I and II coccyx were the most common. Most subjects had four coccygeal vertebrae; 93 subjects (43.66\%) had partial or complete sacrococcygeal fusion. Intercoccygeal fusion was common, occurring in 193 subjects. Eighteen subjects had coccygeal spicules. The mean coccygeal straight length was $33.8 \mathrm{~mm}$ in males and $31.5 \mathrm{~mm}$ in females; the mean sacrococcygeal curvature angle was $116.6^{\circ}$ in males and $111.6^{\circ}$ in females; the mean intercoccygeal curvature angle was $140.94^{\circ}$ in males and $145.10^{\circ}$ in females.

Conclusions: Type I was the most common coccyx type in our study, as in Egyptian and Western populations. The number of coccygeal vertebrae and prevalence of sacrococcygeal and intercoccygeal fusion in the Indian population were similar to those in the Western population. The mean coccygeal straight length and mean sacrococcygeal curvature angle were higher in males, whereas the intercoccygeal curvature angle was higher in females. Information on similarities and differences in coccygeal morphology between different ethnic populations could be useful in imaging and treating patients presenting with coccydynia.

Keywords: Coccyx; Sacrococcygeal; Angle; Computed tomography

\section{Introduction}

The coccyx consists of the terminal vertebral segments of the human spine. Since the human coccyx is considered a vestigial remnant of a tail, it is also referred to as the tailbone. The word coccyx is derived from the Greek word for cuckoo, since that portion of the spine resembles a cuckoo's beak [1]. The human coccyx is variably composed

Received Oct28, 2016; Revised Jan 6, 2017; Accepted Feb 18, 2017

Corresponding author: Venkatraman Indiran

Department of Radiodiagnosis, Sree Balaji Medical College and Hospital, 7 Works Road, Chromepet, Chennai, Tamilnadu 600044, India Tel: +91-44-22653429, Fax: +91-44-22415603, E-mail: ivraman31@gmail.com 
of three to five individual segments or vertebrae. The angulation (curve) of the coccyx and degree of articulation or fusion between individual segments are also variable. The base of the coccyx articulates with the sacrum at the sacrococcygeal junction. The coccyx acts as a weightbearing structure when a person is seated, especially when leaning backward. It also provides positional support to the anus and is the site of insertion of the pelvic floor tendons.

There have been a few studies on the normal in vivo morphology and measurements of the human coccyx in the Western population, but none in the Indian population [2,3]. The coccyx has been studied with the use of cadaveric materials [4], plain radiography [5], computed tomography (CT) [6], and magnetic resonance imaging (MRI) $[3,7]$. According to the Postacchini and Massobrio classification [5], the coccyx is divided into four types: type I, coccyx slightly curved forward with its apex directed downward and caudally; type II, coccyx with more marked forward curvature and forward-pointing apex; type III, coccyx with very sharp forward angulation; and type IV, coccyx showing subluxation at the sacrococcygeal or intercoccygeal joint.

Although coccydynia (pain in the region of the coccyx) usually resolves within a few weeks with or without conservative treatment, it can sometimes be debilitating [8]. Normal reference data on the morphology and measurements of the human coccyx are essential to interpret changes in coccygeal morphology associated with idio- pathic coccydynia. Therefore, we sought to determine coccygeal morphology in the Indian population presenting to our radiology department.

\section{Materials and Methods}

A retrospective, cross-sectional study was performed on 213 patients who presented to our department for abdominal CT scans. Subjects with coccygeal pain or a history of sacrococcygeal trauma were excluded. All other patients presenting for abdominal CT scan (irrespective of the clinical indication for the abdominal scan) were included in this retrospective study. Institutional ethical committee approval was obtained for the study. CT scans were evaluated by radiologists with 10 and 20 years of experience. Non-contrast spiral CT (Hitachi Healthcare Americas, $\mathrm{OH}, \mathrm{USA}$ ) of the abdomen was performed with the automatic exposure control method, and 5-mm sections were obtained. A detector configuration of $4 \times 1.25$ $\mathrm{mm}$ was used to acquire $5-\mathrm{mm}$ sections. These images were reconstructed to 1-mm thickness followed by multiplanar reconstruction. Sagittal images obtained following multiplanar reconstruction were used to assess coccygeal morphology. CT scans were evaluated for number of coccygeal segments, coccyx type (Fig. 1), sacrococcygeal and intercoccygeal joint fusion and subluxation (Fig. 2), coccygeal spicules, sacrococcygeal straight length, and sacrococcygeal and intercoccygeal curvature angles. We sought to study these parameters with respect to differ-
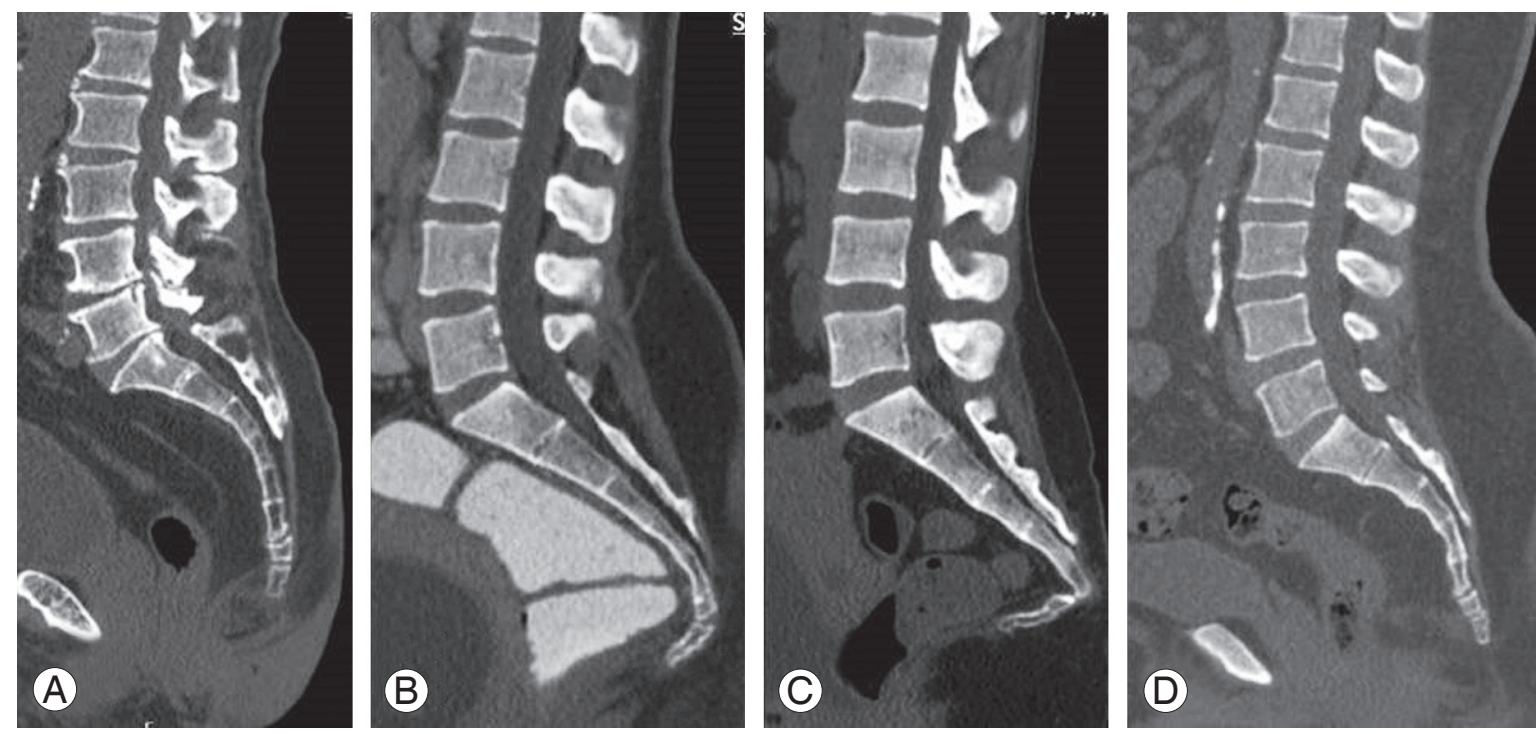

Fig. 1. Sagittal reformats showing (A) type I, (B) type II, (C) type III, and (D) type IV coccyxes 

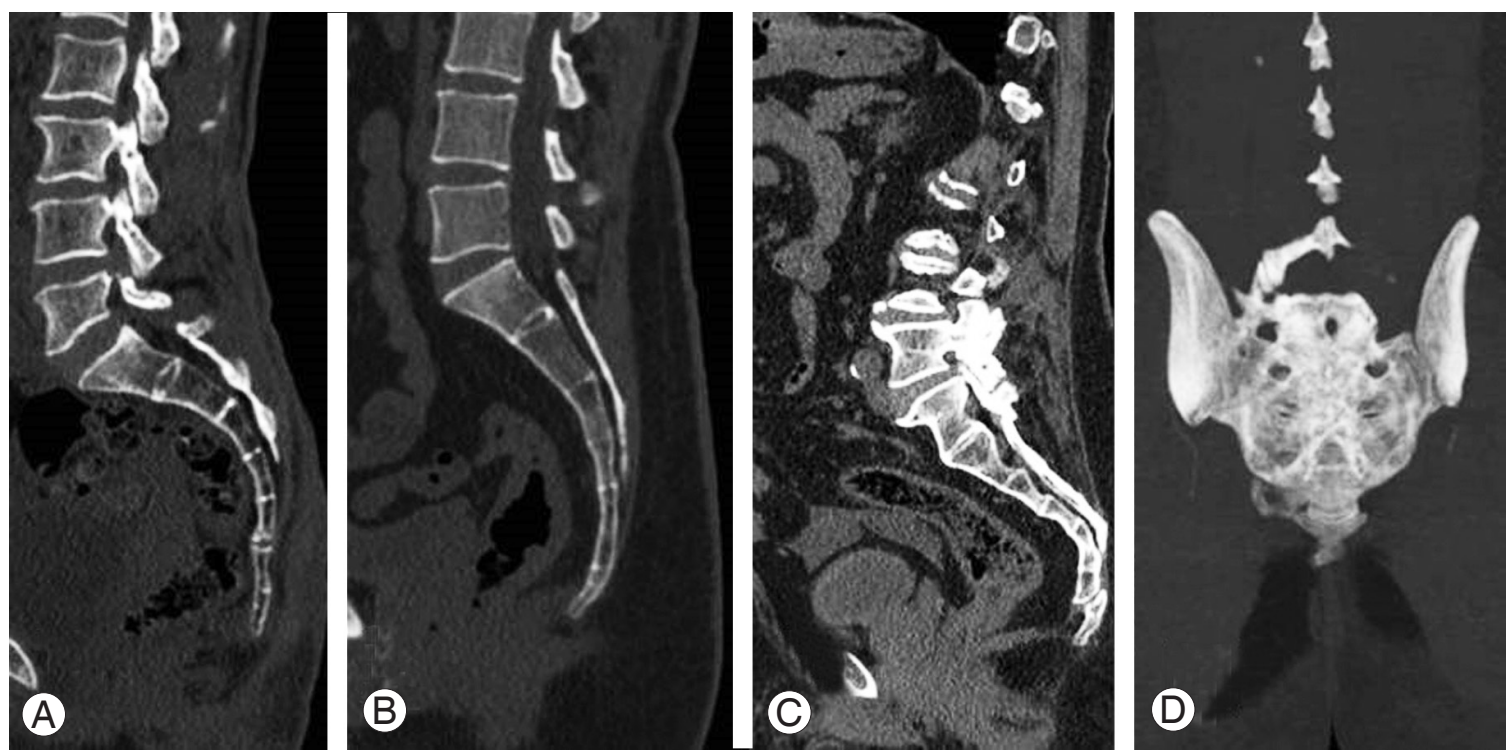

Fig. 2. Sagittal reformats showing (A) intercoccygeal fusion, (B) sacrococcygeal and intercoccygeal fusion, and (C) sacrococcygeal subluxation. (D) Coronal maximum intensity projection image shows lateral deviation of the tip of the coccyx to the right side.

Table 1. Gender distribution of coccyx types and coccy geal segments

\begin{tabular}{|c|c|c|c|c|c|c|c|c|c|c|}
\hline \multirow{3}{*}{ Type } & \multicolumn{5}{|c|}{ Male } & \multicolumn{5}{|c|}{ Female } \\
\hline & \multicolumn{5}{|c|}{ No. of coccygeal segments } & \multicolumn{5}{|c|}{ No. of coccygeal segments } \\
\hline & 2 & 3 & 4 & 5 & Total & 2 & 3 & 4 & 5 & Total \\
\hline 1 & 1 & 11 & 34 & 7 & 53 & 0 & 13 & 24 & 3 & 40 \\
\hline 2 & 0 & 4 & 29 & 8 & 41 & 0 & 2 & 32 & 5 & 39 \\
\hline 3 & 0 & 0 & 3 & 11 & 14 & 1 & 1 & 11 & 2 & 15 \\
\hline 4 & 1 & 3 & 2 & 0 & 6 & 1 & 1 & 2 & 1 & 5 \\
\hline Total & 2 & 18 & 68 & 26 & 114 & 2 & 17 & 69 & 11 & 99 \\
\hline
\end{tabular}

ences in sex and coccyx type. Findings were tabulated and analyzed using Microsoft Excel with appropriate statistical tests (chi-square test). Coccyx type was based on the Postacchini and Massobrio classification. A bone projection arising from the terminal coccygeal segment was termed a coccygeal spicule. Sacrococcygeal curvature angle is the angle formed by the intersection of a line between the midpoint of the upper borders of the first sacral and first coccygeal vertebra and a line between the upper border of the first coccygeal vertebra and the tip of the coccyx. Intercoccygeal curvature angle is the angle formed between lines passing across the middle of the first and last coccygeal segments in the median plane.

\section{Results}

The 213 subjects comprised 114 males and 99 females, with a mean age of 47.3 years (range, 7-88 years). Type I was the most common type (93 subjects), followed by type II ( 80 subjects), type III (29 subjects), and type IV (11 subjects). Types I and II accounted for $43.66 \%$ and $37.55 \%$ of the total, respectively and were the most common types in both males and females (Table 1). The number of coccygeal vertebrae ranged from two to five; 137 subjects had four coccygeal vertebrae, 37 had five, 35 had three, and only 4 had two. Ninety-three subjects (43.66\%) had either partial or complete sacrococcygeal fusion, and 120 (56.33\%) had no sacrococcygeal fusion. Intercoccygeal fusion involving one or more coccygeal vertebrae was 
Table 2. Gender-wise distribution of intercoccygeal fusion, sacrococcygeal fusion, spicules and sacrococcygeal subluxation in different coccyx types

\begin{tabular}{|c|c|c|c|c|c|c|c|c|c|c|c|c|}
\hline \multirow{2}{*}{ Type } & \multicolumn{3}{|c|}{ Intercoccygeal fusion } & \multicolumn{3}{|c|}{ Sacroccoccygeal fusion } & \multicolumn{3}{|c|}{ Spicules } & \multicolumn{3}{|c|}{ Sacrococcygeal subluxation } \\
\hline & Male & Female & Total & Male & Female & Total & Male & Female & Total & Male & Female & Total \\
\hline 1 & 46 & 27 & 73 & 0 & 1 & 1 & 0 & 1 & 1 & 0 & 2 & 2 \\
\hline 2 & 39 & 41 & 80 & 28 & 24 & 52 & 0 & 0 & 0 & 0 & 0 & 0 \\
\hline 3 & 19 & 10 & 29 & 19 & 10 & 29 & 2 & 4 & 6 & 12 & 7 & 19 \\
\hline 4 & 0 & 11 & 11 & 0 & 11 & 11 & 0 & 11 & 11 & 0 & 11 & 11 \\
\hline Total & 104 & 89 & 193 & 47 & 46 & 93 & 2 & 16 & 18 & 12 & 20 & 32 \\
\hline
\end{tabular}

Table 3. Gender-wise distribution of coccyx straight length, mean sacroccoccygeal curvature angle and intercoccygeal angle in different coccyx types

\begin{tabular}{|c|c|c|c|c|c|c|c|c|}
\hline \multirow[b]{2}{*}{ Type } & \multicolumn{4}{|c|}{ Male } & \multicolumn{4}{|c|}{ Female } \\
\hline & Number & $\begin{array}{l}\text { Mean coccyx } \\
\text { straight } \\
\text { length (mm) }\end{array}$ & $\begin{array}{c}\text { Mean sacro } \\
\text { coccygeal } \\
\text { curvature } \\
\text { angle }\left({ }^{\circ}\right)\end{array}$ & $\begin{array}{c}\text { Mean inter } \\
\text { coccygeal } \\
\text { angle }\left({ }^{\circ}\right)\end{array}$ & Number & $\begin{array}{l}\text { Mean coccyx } \\
\text { straight } \\
\text { length } \\
(\mathrm{mm})\end{array}$ & $\begin{array}{c}\text { Mean sacro } \\
\text { coccygeal } \\
\text { curvature } \\
\text { angle }\left({ }^{\circ}\right)\end{array}$ & $\begin{array}{l}\text { Mean inter } \\
\text { coccygeal } \\
\text { angle }\left(^{\circ}\right)\end{array}$ \\
\hline 1 & 53 & 32.87 & 122.73 & 150.05 & 40 & 31.2 & 122.01 & 155.43 \\
\hline 2 & 41 & 34.15 & 109.46 & 134.70 & 39 & 31.52 & 105.41 & 138.36 \\
\hline 3 & 14 & 38.72 & 104.34 & 119.65 & 15 & 32.54 & 89.12 & 126.84 \\
\hline 4 & 6 & 28.28 & 141.66 & 152.68 & 5 & 30.82 & 145.34 & 169.8 \\
\hline Grand total & 114 & 33.81 & 116.69 & 140.94 & 99 & 31.51 & 111.66 & 145.10 \\
\hline
\end{tabular}

seen in 193 subjects, no intercoccygeal fusion was seen in 19 subjects, and the coccyx was completely unossified in 1 subject. Coccygeal spicules were present in only 18 subjects (Table 2). Sacrococcygeal subluxation was seen in 6 subjects. Intercoccygeal subluxation was seen in 26 subjects, with maximum occurrence at the C1-C2 level (19 subjects), followed by the $\mathrm{C} 3-\mathrm{C} 4$ level (6 subjects) and the C2-C3 level (1 subject).

The overall mean coccygeal length was $32.7 \mathrm{~mm}$, with the greatest length of $35.5 \mathrm{~mm}$ in type III coccyxes and the shortest length of $29 \mathrm{~mm}$ in type IV coccyxes. The mean coccygeal straight length was $33.8 \mathrm{~mm}$ in males and $31.5 \mathrm{~mm}$ in females $(p=0.01)$. The mean sacrococcygeal curvature angle was $116.69^{\circ} \pm 13.32^{\circ}$ in males and $111.66^{\circ} \pm 18.45^{\circ}$ in females $(p=0.02)$. The largest sacrococcygeal curvature angles were seen in type IV coccyxes ( $141.6^{\circ}$ in males and $145.34^{\circ}$ in females) and the smallest in type III coccyxes $\left(104.34^{\circ}\right.$ in males and $89.12^{\circ}$ in females). The mean intercoccygeal curvature angle was $140.94^{\circ} \pm 19.83^{\circ}$ in males and $145.10^{\circ} \pm 19.60^{\circ}$ in females $(p=0.12)$. Again, the largest intercoccygeal curvature angles were seen in type IV coccyxes and the smallest in type III coccyxes (Table 3).

\section{Discussion}

The coccyx is a variable structure with varying numbers of vertebrae and alignments. Assessment of its anatomy can be quite exquisite with the use of CT and MRI when compared with plain radiography, which has been the first line of investigation for many years.

Type I was the most common type of coccyx in our study, followed by type II. Similarly, Shalaby et al. [3], in their study on the Egyptian population, found that type I (41.0\%) and type II (31.5\%) were the most common types. Woon et al. [2] found that $64 \%$ of subjects had type I coccyx. Kerimoglu et al. [6] also reported type I to be the most common type, but Przybylski et al. [9], in their study on the Polish population, found type II to be the most common type, followed by type III.

Most subjects in our study (64.3\%) had four coccygeal vertebrae, as was the case with Woon et al. (76\%) [2]. However, Shalaby et al. [3], in their study on the Egyptian population, found that most subjects had three coccygeal 
vertebrae (68.3\%). Similarly Przybylski et al. [9], in their study on the Polish population, found that most subjects had three coccygeal vertebrae (50.8\%).

In our study, 93 subjects ( 47 males and 46 females) had either partial or complete sacrococcygeal fusion (43.66\%). Woon et al. [2] found sacrococcygeal fusion in more than $50 \%$ of their subjects. Tague [10] found no difference between males and females in the prevalence of sacrococcygeal fusion; however, the prevalence increased with aging from $24 \%$ in the third decade to $47 \%$ in the eighth decade. In our study, sacrococcygeal fusion was the most common in type II coccyxes (52 subjects) and least common in type I ( 1 subject), with types III and IV accounting for 29 and 11 cases, respectively.

Intercoccygeal fusion was seen in $90.6 \%$ of subjects in our study (193/213), which is similar to the finding of Woon et al. (89\%) [2]. Males accounted for 104 cases and females accounted for 89 cases. Intercoccygeal fusion was the most common in type II coccyxes (80/213), followed by type I ( $73 / 213)$.

Coccygeal spicules were present in only 18 subjects in our study, with a significant female preponderance. Only two males had coccygeal spicules, both of them with type III coccyxes. Sixteen females had spicules, with a maximum in type IV coccyxes (11 subjects), followed by type III (4 subjects) and type I (1 subject). None of the subjects with type II coccyxes had spicules. Similarly, there was a significant female preponderance of coccygeal spicules in a study of 33 patients undergoing coccygectomy for coccydynia [11,12]. Woon et al. [2] reported a prevalence of coccygeal spicules of $23 \%$, which is quite high compared with the $8.4 \%$ prevalence reported in our study.

In our study, the mean coccygeal straight length was $33.81 \pm 6.97 \mathrm{~mm}$ in males and $31.51 \pm 5.59 \mathrm{~mm}$ in females ( $p=0.009$ ), with the greatest length in type III coccyxes (38.7 and $35.2 \mathrm{~mm}$ in males and females, respectively) and the smallest length in type IV coccyxes (28.28 and 30.82 $\mathrm{mm}$ in males and females, respectively). Similarly, in the study by Woon et al. [2], the mean coccygeal straight length was greater in males $(39 \pm 7 \mathrm{~mm})$ than in females $(36 \pm 7 \mathrm{~mm})$. The mean coccygeal straight length was 32.3 $\mathrm{mm}$ in the Egyptian population [3]. The smallest mean coccygeal straight lengths found in our study were $19 \mathrm{~mm}$ in males and $20 \mathrm{~mm}$ in females. The greatest length found in our study was $50 \mathrm{~mm}$ in both males and females.

The mean sacrococcygeal curvature angle in our study was $116.69^{\circ} \pm 13.32^{\circ}$ in males and $111.66^{\circ} \pm 18.45^{\circ}$ in fe- males $(p=0.02)$. The mean intercoccygeal curvature angle was $140.94^{\circ}+19.83^{\circ}$ in males and $145.10 \pm 19.60^{\circ}$ in females $(p=0.12$ ). Both sacrococcygeal and intercoccygeal curvature angles were the greatest in type IV coccyxes and smallest in type III coccyxes. Woon et al. [2] reported that the overall mean sacrococcygeal curvature angle was $106^{\circ} \pm 13^{\circ}$, with no significant difference between males and females. However, they found that the coccygeal curvature was greater in males than in females $\left(168^{\circ}\right.$ and $164^{\circ}$ in males and females, respectively). In the Egyptian population, the mean sacrococcygeal curvature angle was $110.69^{\circ}$ in males and $109^{\circ}$ in females, with no significant sex difference [3]. Przybylski et al. [9] reported a mean intercoccygeal curvature angle of $51^{\circ} \pm 23.3^{\circ}$. Kerimoglu et al. [6] reported a mean intercoccygeal curvature angle of $72.1^{\circ} \pm 31.86^{\circ}$. Kim and Suk [13] estimated the mean intercoccygeal curvature angle as $128^{\circ}$ based on radiographs of 20 Korean adults. In a retrospective analysis of 606 pelvic CT scans in Korean patients, the average sacrococcygeal and intercoccygeal curvature angles were found to be $110^{\circ}$ and $49^{\circ}$, respectively. Type II coccyx was the most common in that ethnic group. Sacrococcygeal fusion was found in $34 \%$ of the sample [14]. Lee et al. [15], in their morphometric study of the coccyx using three-dimensional reconstruction in 136 normal adult pelvises, found that most of the measured coccyx parameters were larger in males than in females, with the exception of sacrococcygeal and intercoccygeal curvature angles.

In our study, lateral deviation of the coccyx was seen in only 10 ( 7 males and 3 females) of the 213 subjects. Of these, four were deviated to the left side and six to the right side. The deviation ranged from 4 to $11^{\circ}$, with a mean of $5.95^{\circ}$. The mean deviation was $5.78^{\circ}$ in males and $6.33^{\circ}$ in females, with no statistically significant difference between the sexes $(p=0.72)$. Woon et al. [2] reported that the tip of the coccyx was deviated laterally by a mean of $6^{\circ}$, with a higher degree of deviation in men.

In summary, there are similarities as well as differences in coccygeal morphology among different ethnic populations. There could also be differences among different populations in coccygeal morphology of patients with coccydynia. Further studies on the coccygeal morphology of Indian patients with coccydynia may throw more light on the correlation between coccygeal morphology and coccydynia.

A limitation of this study is that it was based on convenience sampling of patients presenting for $\mathrm{CT}$ rather 
than being a population-based study. Another limitation is that measurements and observations were made with the coccyx in a static position and the patient in a supine position. Sitting and standing may alter the sacrococcygeal and intercoccygeal curvature angles. A study using dynamic imaging may also be necessary.

\section{Conclusions}

Type I was the most common coccyx type in our study, followed by type II, as seen in the Egyptian and Western populations and unlike the Polish population. Most of the subjects in our study had four coccygeal vertebrae, as was the case in the Western population but not in the Egyptian and Polish populations. The prevalence of partial or complete sacrococcygeal fusion in the Indian population was similar to that in the Western population. Intercoccygeal fusion was very common, as in the Western population. The prevalence of coccygeal spicules was lower in the Indian population than in the Western population. The mean coccygeal straight length was significantly greater in males than in females, as was also seen in Western and Egyptian populations. The mean sacrococcygeal curvature angle was significantly greater in males than in females in our study, unlike in the Western population. However, the intercoccygeal curvature angle was greater in females than in males, although the difference was not statistically significant, again unlike in the Western population. Most of the coccygeal parameters in the Indian population were similar to those in the Western population, except for sacrococcygeal and intercoccygeal curvature angles. Data on coccygeal morphometry in patients without coccygeal pain could help us establish normal values for the Indian population and could be useful in imaging and treating patients presenting with coccydynia.

\section{Conflict of Interest}

No potential conflict of interest relevant to this article was reported.

\section{References}

1. Howorth B. The painful coccyx. Clin Orthop 1959;14:145-60.

2. Woon JT, Perumal V, Maigne JY, Stringer MD. CT morphology and morphometry of the normal adult coccyx. Eur Spine J 2013;22:863-70.

3. Shalaby SA, Eid EM, Allam OA, Ali AM, Gebba MA. Morphometric study of the normal Egyptian coccyx from (age 1-40 year). Int J Clin Dev Anat 2015;1:32-41.

4. Woon JT, Stringer MD. Clinical anatomy of the coccyx: a systematic review. Clin Anat 2012;25:158-67.

5. Postacchini F, Massobrio M. Idiopathic coccygodynia: analysis of of fifty-one operative cases and a radiographic study of the normal coccyx. J Bone Joint Surg Am 1983;65:1116-24.

6. Kerimoglu U, Dagoglu MG, Ergen FB. Intercoccygeal angle and type of coccyx in asymptomatic patients. Surg Radiol Anat 2007;29:683-7.

7. Woon JT, Maigne JY, Perumal V, Stringer MD. Magnetic resonance imaging morphology and morphometry of the coccyx in coccydynia. Spine (Phila Pa 1976) 2013;38:E1437-45.

8. Lirette LS, Chaiban G, Tolba R, Eissa H. Coccydynia: an overview of the anatomy, etiology, and treatment of coccyx pain. Ochsner J 2014;14:84-7.

9. Przybylski P, Pankowicz M, Bockowska A, et al. Evaluation of coccygeal bone variability, intercoccygeal and lumbo-sacral angles in asymptomatic patients in multislice computed tomography. Anat Sci Int 2013;88:204-11.

10. Tague RG. Fusion of coccyx to sacrum in humans: prevalence, correlates, and effect on pelvic size, with obstetrical and evolutionary implications. Am J Phys Anthropol 2011;145:426-37.

11. Doursounian L, Maigne JY, Jacquot F. Coccygectomy for coccygeal spicule: a study of 33 cases. Eur Spine J 2015;24:1102-8.

12. Maigne JY, Doursounian L, Chatellier G. Causes and mechanisms of common coccydynia: role of body mass index and coccygeal trauma. Spine (Phila $\mathrm{Pa}$ 1976) 2000;25:3072-9.

13. Kim NH, Suk KS. Clinical and radiological differences between traumatic and idiopathic coccygodynia. Yonsei Med J 1999;40:215-20.

14. Yoon MG, Moon MS, Park BK, Lee H, Kim DH. Analysis of sacrococcygeal morphology in Korean by using computed tomography. Clin Orthop Surg 2016;8:412-9.

15. Lee JY, Gil YC, Shin KJ, et al. An anatomical and morphometric study of the coccyx using three-dimensional reconstruction. Anat Rec (Hoboken) 2016;299:307-12. 